\title{
Functional and Anatomical Outcome of Unstable Extra-Articular Distal Radius Fracture Managed with Plaster Immobilization and with External Fixation
}

\author{
Authors \\ Dr N.Karthikeyan, Dr P.Subramani \\ GMKMC, Salem.
}

\begin{abstract}
This is a prospective study aimed to analyse the functional and anatomical outcome of adult unstable extra articulat fracture distal radius treated with Plaster and External fixation. Of the 48 patients, 23 were treated with external fixation and the rest with plaster. The anatomical results were analysed using Lindstrom \& Frykmann Grading and the functional outcomes with Gartland \& Werly demerit scoring system. The study showed that External fixation gives better anatomical and functional results in unstable extra articular distal Radius fractures.
\end{abstract}

\section{Introduction}

Fractures of the distal radius are one of the most common fractures seen in an emergency department. Fracture of the distal radius being a common fracture and closed in most cases, has long been treated by closed reduction and cast application. Although cast does provide support, it will not completely maintain a reduction. Hence, in a majority of cases, satisfactory reduction will reangle or redisplace in an immobilizing cast resulting in a poor functional outcome.

Displaced fractures of distal radius are considered unstable when alignment cannot be maintained in a forearm plaster after closed reduction, but this definition applies retrospectively.

For an extra articular fracture, either one of the following features

1. Dorsal angulation more than 20 degrees

2. Dorsal communication more than $50 \%$ of width
3. Radial shortening of more than $5 \mathrm{~mm}$

4. Volar Comminution

5. Translation more than $1 \mathrm{~cm}$.

6. Severe osteoporosis

on initial presentation indicates instability.

For an unstable extra articular fracture of distal radius percutaneous pinning has been recommended as a simple way of providing additional stability to immobilization in cast. Percutaneous pinning has all the disadvantages of external fixator like inability to achieve direct reduction, immobilization of radio carpal joint and pin tract infections. It also lacks some of the advantages of external fixators like adjustability, known strength and reusability for a specific patient.

External fixation for distal radius fracture relies on the principle of Ligamentotaxis in which, a distraction force applied to the carpus aligns the fragments by means of intact ligaments. 
Distraction assisted reduction and maintenance of distal radius fracture is a widely used and reliable treatment method.

\section{Materials and Methods}

This is a randomized prospective study conducted in Government Mohan Kumaramangalam Medical College Hospital, Salem June 2013 to June 2016.

Skeletally mature patients with potentially unstable dorsally angulated extra-articular fracture of distal radial metaphysis of AO type A2 or A3 were enrolled in this study.

Patients with open fracture, stable fracture with dorsal angulation $<20^{\circ}$, intra articular fracture, volar angulated fracture, previous ipsilateral or contralateral fracture of wrist and patients with dementia or psychiatric illness were excluded from study.

The patients were randomly divided into two groups. All procedures were carried out under brachial plexus block or intravenous anaesthesia within 72 hours after injury. After closed reduction, to maintain reduction, cast immobilization was applied in twenty five patients and external fixation was applied in twenty three patients.

A successful reduction is defined as step deformity of $2 \mathrm{~mm}$ or less, neutral palmar tilt or better and radial shortening of less than $5 \mathrm{~mm}$ as compared to normal side.

\section{Closed Reduction and Cast Immobilization}

Closed reduction was achieved by longitudinal traction and gentle manipulation. With longitudinal traction and slight extension forces, fracture was disimpacted. With continuous traction across the fracture site, flexion and ulnar deviation forces were applied to reduce the distal fragment. Finally the fracture was locked in place by applying pronation, flexion and ulnar deviation forces. A dorso-radial below elbow slab was applied with wrist in slight flexion, slight ulnar deviation and pronation.

\section{Closed Reduction and External Fixation}

In external fixation (ligamentotaxis) group, the fracture reduction was first achieved under anaesthesia by the same method as for closed reduction group. Then, the limb was painted and draped. External fixator was applied with two $2.5 \mathrm{~mm}$ Schanz pins in the second metacarpal and two $3.5 \mathrm{~mm}$ Schanz pins in the shaft of Radius in $30^{\circ}$ dorso lateral plane. The pins are connected with multiaxial clamp and a distraction rod with reduction in place.

All patients in both the groups were encouraged to move the fingers from the first day. All were taught the Six Pack Finger excercises. The patients were reviewed every week. At the end of six weeks the POP or the external fixators were removed and wrist mobilization started.

Then the patients were reviewed monthly for three months and every two months for a year. Every time functional and radiological assessment were made and compared to the normal side.

\section{Observations and Results}

Forty eight patients were enrolled in this study. Twenty five patients were treated with cast immobilization and twenty three patients with external fixation. Of them seventeen were males and thirty one were females. The mean age is 49.5 years for males and 50.3 years for females. The dominant side was involved in $39 \%$ in external fixation group and $44 \%$ in cast immobilization group.

The mean duration between injury and procedure was two days. In external fixation group, two patients $(8.6 \%)$ developed pin site infection necessitating pin removal at five weeks in one patient. One patient developed radial sensory nerve deficit. No patient developed metacarpal fracture, median nerve deficit or tendon problem.

At follow up, patients were evaluated for pain, working ability, grip strength and complications like stiffness, deformity and reflex sympathetic dystrophy.

The range of palmar flexion, extension, radial and ulnar deviation, supination, pronation and grip 


\section{JMSCR Vol||05||Issue ||08||Page 27256-27259||August}

strength were noted and compared with opposite side.

Both wrists were radiographed and parameters were compared. Paired samples $\mathrm{T}$ test showed both methods of treatment produced statistically significant results.

\section{Paired Samples T Test}

\begin{tabular}{|l|c|c|c|}
\hline Variable & Procedure & $\begin{array}{c}\text { Mean Difference(Pre- } \\
\text { Reduction And One Year) }\end{array}$ & P Value \\
\hline Radial Length & Cast Immobilization & 4.96 & $<0.0005$ \\
\cline { 2 - 4 } & External Fixation & 7.31 & $<0.0005$ \\
\hline \multirow{2}{*}{ Volar Tilt } & Cast Immobilization & 10.04 & $<0.0005$ \\
\cline { 2 - 4 } & External Fixation & 29.37 & $<0.0005$ \\
\hline Radial Angulation & Cast Immobilization & 4.16 & $<0.0005$ \\
\cline { 2 - 4 } & External Fixation & 9.00 & $<0.0005$ \\
\hline Ulnar Variance & Cast Immobilization & -2.04 & $<0.0005$ \\
\cline { 2 - 4 } & External Fixation & -2.81 & $<0.0005$ \\
\hline
\end{tabular}

One sample $\mathrm{T}$ test for External Fixation showed that results produced are so significant that
External Fixation gave far better results when compared to cast immobilization group.

\section{One Sample T Test - External Fixation}

\begin{tabular}{|c|c|c|c|c|c|c|c|}
\hline & \multirow[t]{2}{*}{$\begin{array}{c}\text { Test } \\
\text { Value }\end{array}$} & \multirow[t]{2}{*}{ Test } & \multirow[t]{2}{*}{ df } & \multirow[t]{2}{*}{$\begin{array}{l}\text { Sig.(2- } \\
\text { tailed) }\end{array}$} & \multirow[t]{2}{*}{ Meandifference } & \multicolumn{2}{|c|}{$\begin{array}{l}95 \% \text { confidence interval } \\
\text { of the difference }\end{array}$} \\
\hline & & & & & & lower & Upper \\
\hline Radial Length & 7.92 & 3.457 & 15 & 0.004 & 2.3300 & O.8936 & 3.7664 \\
\hline Volar Tilt & 13.32 & 13.876 & 15 & 0.000 & 16.3200 & 13.8131 & 18.8269 \\
\hline Radial Angulation & 16.92 & 9.749 & 15 & 0.000 & 3.1425 & 2.4554 & 3.8296 \\
\hline Ulnar Variance & 2.48 & -7.226 & 15 & 0.000 & -1.5425 & -1.9975 & -1.0875 \\
\hline
\end{tabular}

In external fixation group, at one year, $81.25 \%$ patients had no pain and $87.5 \%$ patients returned to regular work. But in cast immobilization group, $72 \%$ patients had mild or moderate pain and only $56 \%$ patients returned to regular work. At one year none in external fixation had stiffness, and four patients in cast immobilization had stiffness. The patients were evaluated as per modified criteria suggested by Gartland and Werley for functional assessment. In external fixation group six patients (28.\%) had excellent results and thirteen $(61.9 \%)$ had good results. In cast immobilization group, none had excellent result, five $(20 \%)$ had good result, nineteen $(76 \%)$ had fair result and one (4\%) had poor result.

Anatomic or radiological evaluation was done as per Lindstrom and Frykmann criteria. In external fixation group, eighteen $(85.7 \%)$ had grade I i.e. no deformity and remaining grade II i.e. mild deformity. In cast immobilization group, only one patient (4\%) had grade one result and fifteen patients $(60 \%)$ had grade III or IV result.

On functional analysis based on Gartland and Werley demerit system, $90.5 \%$ of patients in external fixation group had excellent to good results but only $20 \%$ patients in cast immobilization group had good results. There was no poor result in external fixation group, but one patient in cast immobilization group had poor result.

In our study, on anatomical or Radiological grading by Lindstrom and Frykman system, $85.7 \%$ patients in external fixation group had grade I result i.e. no significant deformity. But only one patient in cast immobilization group was able to get grade I result and $60 \%$ of patients produced only grade III or IV results.

At six months, three patients $(14.3 \%)$ in external fixation group had stiffness, whereas, almost half 
of the patients in cast immobilization group had stiffness.

Thus, closed reduction and maintenance of reduction with external fixation produced far better results than cast immobilization for an unstable extraarticular distal radius fracture. External fixation is a simple and easy technique with low complication rate.

Restoration of normal anatomy is important for restoration of function. Normally $82 \%$ of the compressive load across the wrist is borne by distal radius and remaining by distal ulna. With $2.5 \mathrm{~mm}$ loss of radial length, ulna bears $42 \%$ load and at 20 degree dorsal angulation, ulna bears $50 \%$ load.

Preservation of radial length is the most important factor for preservation of function. Loss of radial length can lead to ulnar impaction or dysfunction of Distal Radio Ulnar Joint. Residual dorsal angulation can precipitate ulnar impaction, midcarpal instability and altered stress concentration which may lead to early arthritis.

Fractures of the distal radius though common and appear simple, affect the function of the wrist considerably. It is the commonest fracture seen in the outpatient department and most are treated with plaster immobilization. Most of these fractures are unstable resulting in loss of reduction and hence malunion, altered wrist kinematics, poor range of motion and early arthritis.

In an unstable dorsally angulated extraarticular distal radius fracture, external fixation applying the principle of ligamentotaxis gives good to excellent results with minimal complications. Applying external fixator in a 30 degree dorsal plane allows early finger movements. Six pack exercises while fixator in place, prevent finger stiffness. Simple and sincere pin site care will prevent any pin related complication.

\section{References}

1. Paul A Vaughan, spenser M Lui, Ian J. Harrington: Treatment of unstable fracture of distal radius by external fixation -
Journal of Bone and Joint Surgery 1985 67-B, no.3, 385-389.

2. William A Grann, Joseph A Kopta : the Roger Anderson device in the treatment of fracture of distal end of radius - Journal of Bone and Joint Surgery 1979 Dec. 12341238.

3. Daniel A Rikli, Karl Kupfer and Andras Bodoky: Long term results of external fixation of distal radius fractures - Journal of Trauma vol 44 no.6; 970-976.

4. Robert M Szab : Extra articular fracture distal radius - Orthopaedic Clinics of North America April 1993 vol 24, no.2, 229-237.

5. G.S.Roysam: The distal radio ulnar joint in colles fracture. - Journal of Bone and Joint Surgery (Br) 1993; 75-B, 58-60.

6. J.J Dias, C.C Wray, J.M Jones, P.J.Gregg: The value of early mobilization in the treatment of colles fractures. - Journal of Bone and Joint Surgery(Br) 1987, 69-B; 463-467.

7. William P. Cooney, James H. Dobyns, Ronald L Linscheid: Complications of Colles fracture. - Journal of Bone and Joint Surgery 1980, 62-A, no.4, 613-619.

8. P.J.Mackenney, M.M. McQueen, R.Elton: Prediction of instability in distal radius fracture. - Journal of Bone and Joint Surgery 2006. 88-A, no.9, 1944-1951.

9. John J.Gartland and Charles W.Werley: Evaluation of healed Colles fracture.Journal of Bone and Joint Surgery (Am) 1951; 33: 895-907.

10. M.M.McQueen, C.Hajducka, C.M.Court Brown: Redisplaced unstable fractures of distal radius - Journal of Bone and Joint Surgery (Br) 1996; 78-B, 404-409. 